\title{
NOVAS TECNOLOGIAS E CONFIANÇA NAS ORGANIZAÇÕES: UM ESTUDO DE CASO NO CONTEXTO HOSPITALAR
}

Ana Carolina S. Queiroz 1

Daniel Augusto Moreira 2

\begin{abstract}
Resumo: A implementação crescente de novas tecnologias em todos os setores da economia aumentou o grau de complexidade e incerteza organizacional e, como resultado, fez emergir novos desafios para as empresas e seus membros. $O$ presente trabalho analisa a implementação de tecnologia no departamento de radioterapia de uma instituição hospitalar privada de grande porte. 0 principal objetivo foi verificar se 0 aumento da complexidade organizacional, oriunda do emprego crescente de novas tecnologias, é acompanhado por uma redefinição das relações de confiança na instituição hospitalar. Ademais, pretendeu-se investigar o papel da confiança na condição de variável social de adaptação das organizações às exigências do meio ambiente.
\end{abstract}

Palavras-chave: Estudos Organizacionais. Inovação. Novas Tecnologias. Confiança.

\section{INTRODUÇÃO}

A implementação crescente de novas tecnologias em todos os setores da economia aumentou o grau de complexidade organizacional e, como resultado, fez emergir novos desafios para as empresas e seus membros. As novas tecnologias, ou tecnologias da informação introduzem um conjunto de novos aspectos organizacionais não contemplados anteriormente por teóricos da área de Organizações (BARLEY, 1986; WEICK, 2001; ZUBOFF, 1988). Para que se possa compreender as novas tecnologias, seu potencial inovador e seus efeitos sobre as variáveis organizacionais, é preciso revisar os conceitos tradicionais da Teoria das Organizações e propor novas abordagens (BARLEY, 1986; WEICK, 2001a; ZUBOFF, 1988).

O termo 'novas tecnologias' engloba diversos desenvolvimentos tecnológicos realizados nos últimos vinte anos, tais como a ciência da computação, a microeletrônica, as telecomunicações, a engenharia de software e a análise de sistemas. As novas tecnologias aumentam a capacidade de registrar, armazenar, analisar e transmitir grandes volumes de informações complexas de maneira segura, flexível, confiável, imediata e com independência geográfica. A tecnologia da informação tem sido capaz de transformar e re-estruturar operações que fazem uso de informações para realizar transações, acompanhar registros, desenvolver análises, controlar e comunicar.

Quase todos os setores da economia mundial foram permeados por algum tipo de tecnologia da informação. Na indústria hospitalar, não tem sido diferente. Nos últimos trinta anos, tem-se assistido a uma revolução tecnológica sem precedentes nas áreas diagnóstica, terapêutica e administrativa de tais instituições. Como resultado, houve um aumento na complexidade e no grau de incerteza organizacional. As tecnologias médico-hospitalares disponibilizam uma quantidade enorme de novas

\footnotetext{
1 Departamento de Pós-Graduação em Administração, UNINOVE, São Paulo, SP. E-mail: acqjam @ uol.com.br.

2 Departamento de Pós-Graduação em Administração, UNINOVE, São Paulo, SP. E-mail: dmoreira@uninove.br
} 
informações clínicas, as quais precisam ser compreendidas e pesquisadas para que seu potencial de cura seja explorado. Dessa forma, as profissões da saúde tornam-se mais especializadas, há um número maior de profissionais envolvidos no processo da assistência e uma crescente divisão de trabalho.

Este trabalho tem por objetivo verificar se o aumento da complexidade organizacional, oriunda do emprego crescente de novas tecnologias, é acompanhado por uma redefinição das relações de confiança na instituição hospitalar. Adicionalmente, pretende-se investigar o papel da confiança na condição de variável social de adaptação das organizações às exigências do meio ambiente.

A estratégia de pesquisa adotada foi um estudo caso de implementação de novas tecnologias para tratamento de radioterapia de um hospital privado de grande porte, na cidade de São Paulo, Brasil. Os dados foram obtidos através de entrevistas semi-estruturadas aplicadas a profissionais que trabalham com as novas tecnologias, são afetados por elas ou estiveram envolvidos no processo de decisão de compra e implementação das mesmas. Este estudo de caso fez parte de uma pesquisa mais ampla para a qual setenta entrevistas foram realizadas.

\section{O ESTUDO DE CASO}

\subsection{A PESQUISA}

O estudo de caso foi desenvolvido através de entrevistas individuais, observação de pessoas trabalhando com as novas tecnologias e análise de documentos.

Foram realizadas entrevistas com médicos, físicos, biomédicos e técnicos em radioterapia. Essas entrevistas representaram, aproximadamente, $72 \%$ dos profissionais envolvidos com as tecnologias empregadas nos tratamentos de radioterapia do hospital. Foram entrevistados, também, dois profissionais externos à unidade de radioterapia: um profissional que participou da idealização e implementação da unidade médica estudada e um profissional da gerência administrativa da instituição.

A amostra foi selecionada para que houvesse representatividade das principais funções afetadas pelas novas tecnologias. Dessa forma, a amostra engloba entrevistas com todos os médicos que trabalham na unidade, todos os coordenadores (biomédicos) da operação, o coordenador (físico) de planejamento e qualidade, além de operadores e físicos. Os entrevistados possuíam uma idade média de trinta e quatro anos e tempo médio de vínculo com a instituição de cinco anos e meio.

Para complementar as informações obtidas nas entrevistas e verificá-las na rotina de trabalho, aplicou-se o método de observação passiva. Duas situações distintas foram observadas: a aplicação de tratamentos de radioterapia por parte dos operadores, cuja duração é de aproximadamente vinte minutos e a simulação realizada antes de se iniciar os tratamentos, que pode ter uma duração de sete a dez dias de trabalho, dependendo da complexidade do caso.

A documentação analisada compreendeu os prontuários de pacientes, a documentação suporte da equipe de planejamento, as apresentações de operadores em congressos de radioterapia e a documentação do sistema de gerenciamento, o VARIS. Os prontuários continham as seguintes informações: a solicitação do médico particular para tratamento e a descrição da situação do paciente, a avaliação do médico responsável no hospital, as fotos do paciente e do local físico do tratamento, exames de imagem e laboratoriais, as simulações, o planejamento do tratamento e todos os registros pertinentes ao tratamento efetuado. 


\subsection{OS RESULTADOS}

O serviço de radioterapia do hospital estudado possui cerca de dez anos de existência. A unidade médica foi criada em 1993, pela direção da instituição, com o objetivo de desenvolver e manter o serviço mais avançado do Brasil para tratamento de radioterapia contra o câncer. Para tanto, as mais modernas tecnologias comercialmente disponíveis nos Estados Unidos, e dentro dos padrões estabelecidos de tratamento (patterns of care), foram adquiridas, testadas e implementadas. Houve, também, um importante investimento na contratação e treinamento de profissionais para desenvolver e manter uma equipe integrada e envolvida em todas as etapas do processo de tratamento. Há evidências para afirmar que a estratégia dessa unidade médica tem quatro pontos chaves:

a) Atualização contínua das tecnologias empregadas. Ou seja, incorporar as novas tecnologias que tenham sido desenvolvidas e testadas nos Estados Unidos, local onde, atualmente, há maior avanço tecnológico na área, de acordo com os médicos e os físicos entrevistados. Tais tecnologias englobam a atualização de softwares e de equipamentos.

b) Ênfase no trabalho de equipe e multi-profissional. Os médicos têm o suporte de uma equipe composta por físicos e biomédicos com pós-graduação em radioterapia e técnicos com vários anos de experiência em serviços similares em outros hospitais e clínicas. Além de estarem diretamente envolvidos no planejamento e execução do tratamento, há evidências de que a responsabilidade pelo tratamento é adequadamente compartilhada entre os membros da equipe. De acordo com um dos médicos entrevistados, "[...] a equipe deve funcionar como uma equipe de fórmula um, o sucesso do tratamento depende da harmonização dos trabalhos dos médicos, físicos, biomédicos e técnicos [...]".

c) Treinamento e Educação Continuada. A área de radioterapia contém um programa próprio de treinamento continuado que contempla a utilização das tecnologias, aprimoramento de procedimentos operacionais e aulas com médicos e físicos para compartilhar conhecimentos sobre os tratamentos, suas especificidades e novos progressos científicos na área. Além disso, há incentivos para estimular a pesquisa e os trabalhos científicos.

d) Busca permanente de redução dos riscos relacionados ao tratamento, o que permite considerá-la uma organização de alta confiabilidade. De acordo com relatos dos profissionais entrevistados, as novas tecnologias criam a oportunidade de se oferecer ao paciente um tratamento mais eficiente, com mais chances de cura e menos efeitos colaterais. No entanto, se mal utilizada, a tecnologia poderá causar danos adicionais à saúde. Em função disso, existe a preocupação constante de reduzir os riscos aos quais 0 paciente é exposto. Para tanto, o hospital trabalha com um número médio de pacientes por equipamento até cinco vezes menor que em outras instituições do Brasil e com um tempo médio de aplicação da radioterapia de vinte minutos, contra os dez minutos de seus concorrentes. Há, ainda, uma ênfase na fase de planejamento do tratamento e a existência de um sistema gerencial, denominado VARIS, que foi implementado em 2000, para registrar e controlar todas as etapas do tratamento. Percebe-se, nas entrevistas, que os funcionários possuem uma preocupação constante com a redução de risco e a busca de melhorias contínuas no tratamento, cujo principal objetivo é concentrar a radiação no local da lesão, evitando danos aos órgãos que estão próximos da mesma. Atualmente, a margem de erro é, de no máximo, um milímetro. Há evidências para concluir que a busca da exatidão é quase uma obsessão para os profissionais dessa área do hospital, nas palavras de um técnico "é uma briga diária para fazer desaparecer aquele milímetro". 
Segundo entrevistados que estiveram envolvidos com a implementação desse serviço no hospital, a unidade de radioterapia foi estruturada e planejada após a realização de inúmeras visitas a hospitais americanos, reconhecidos pela qualidade dos serviços na área. Os profissionais que participaram da implementação avaliaram as tecnologias disponíveis, os fornecedores, a estrutura organizacional dos hospitais visitados e os respectivos procedimentos operacionais. O hospital realizou investimentos financeiros importantes para que essa unidade médica pudesse começar a prestar serviços com o mais alto padrão de qualidade e, posteriormente, tivesse condições de mantê-los. Como resultado, o preço de um tratamento de radioterapia nessa instituição é mais alto do que a média de mercado, o que acaba por atrair pacientes com um alto poder aquisitivo, geralmente das classes $\mathrm{Ae}$ B.

Na percepção de alguns entrevistados, os pacientes tratados nesse hospital possuem um nível educacional que Ihes permite fazer questionamentos acerca do tratamento e sua relação de custo/benefício, além de muitos pacientes da radioterapia carregarem uma forte carga emocional, dada sua situação de saúde, o que tende a aumentar o nível e o tom das exigências. Nos relatos e nas ações dos funcionários, há evidências para concluir que o grau de exigência dos pacientes é uma fonte importante de motivação para a busca da redução dos riscos e para o comprometimento da equipe, porém é, também, uma causa de estresse no trabalho.

Nesse contexto, é importante, ainda, destacar as principais características da relação entre os médicos e os outros profissionais da saúde na radioterapia. Os médicos são funcionários do hospital em tempo integral, dedicam-se à definição do tratamento e ao acompanhamento periódico do paciente. Além disso, dirigem as atividades de planejamento e simulação, desempenhadas pelos físicos, e acompanham diariamente a aplicação do tratamento realizado pela equipe operacional, a qual é coordenada pelos biomédicos. $O$ acompanhamento da aplicação dá-se através do uso de radiografias (portal-films), as quais retratam a posição do paciente durante o tratamento e, uma vez por semana, pelo acompanhamento do tratamento 'in-loco' para verificar o posicionamento do paciente, monitorar os efeitos colaterais, avaliar a resposta do tumor, prescrever medicações e passar as orientações necessárias.

Os relatos colhidos nas entrevistas e os dados obtidos pelo método da observação indicam que a orientação proporcionada pelos médicos aos outros profissionais é fundamental para 0 bom desempenho dos trabalhos. Essa orientação não apresenta caráter de centralização de autoridade para exercício de poder. Há uma confiança mútua entre as partes que, de um lado, permite a delegação de responsabilidades do médico para funcionários $e$, de outro, o respeito dos funcionários pelos conhecimentos médicos adquiridos através da educação formal, da pesquisa e da experiência prática. Por parte dos médicos, há um interesse latente em transmitir continuamente novos conhecimentos aos funcionários, com o objetivo de minimizar erros e aumentar a qualidade dos tratamentos, reduzindo, assim, seu grau de responsabilidade. Por parte dos funcionários, percebe-se um comprometimento com o aprendizado e com a busca de perfeição nas atividades que lhes cabe. Dessa forma, observa-se uma distribuição eqüitativa de autoridade e responsabilidades, compatíveis com as funções, bem como um alto grau de comprometimento que facilita o trabalho em equipe.

Por fim, é importante ressaltar que os relatos dos integrantes da equipe de operações, biomédicos e técnicos, contribuíram de forma significativa para o levantamento de informações sobre 0 serviço estudado em relação a outros disponíveis no Brasil. Eles, por lei, não podem trabalhar em um serviço de radioterapia por mais de quatro horas por dia, pois a radiação representa um risco a sua saúde. Como a instituição estudada optou por não se expor a riscos trabalhistas, a área tem dois grupos de operadores, um que aplica os tratamentos no período da manhã e outro que os aplica no período da tarde. Cada grupo é coordenado por um biomédico diferente. As comparações, efetuadas por esses profissionais, entre o hospital em estudo e as outras instituições em que atuam diariamente, demonstram que há consenso sobre as seguintes constatações: 
a) O hospital em estudo esteve sempre à frente de outras instituições na compra e implementação de novas tecnologias. Nos últimos três anos, no entanto, houve um barateamento dessas tecnologias, o que permitiu que os outros hospitais e clínicas viessem a adquiri-las rapidamente. Porém, nenhuma outra instituição, na qual esses profissionais atuam, possui um conjunto tão completo de tecnologias.

b) Um dos diferenciais do hospital está na sua estrutura organizacional. De acordo com os operadores, nos outros serviços as equipes são compostas apenas por médicos e técnicos em radioterapia. Não há o apoio dos físicos, biomédicos, enfermeiras, nutricionistas e psicólogos. Além disso, o número de pacientes atendidos pelo profissional é superior nos outros locais onde trabalham.

c) Outro diferencial apontado é a ênfase na fase do planejamento e no trabalho em equipe. Nas outras instituições, não há a etapa de planejamento e simulação para os tratamentos de radioterapia. $O$ médico indica o tratamento e o técnico em radioterapia o executa. Para os profissionais entrevistados, isso acarreta maior probabilidade de erros, principalmente porque não existe uma equipe co-responsável que acompanhe todas as etapas do processo e auxilie na redução de riscos. Nos relatos dos entrevistados, há evidências para concluir que os técnicos e biomédicos, quando em outras instituições, realizam os trabalhos isoladamente, com pouca interferência de outros profissionais, inclusive dos médicos.

d) As outras instituições não possuem um sistema de gerenciamento similar ao VARIS. Esse sistema permite 0 registro de todos os dados referentes ao tratamento de um paciente, desde a primeira consulta até a última aplicação de radioterapia. De acordo com os operadores, uma das principais vantagens do VARIS é a capacidade de armazenar os parâmetros de tratamento definidos na fase de planejamento e controlar a aplicação da radioterapia.

e) Apesar de a responsabilidade no serviço ser compartilhada, em contraposição aos outros hospitais e clínicas, nas quais o profissional técnico assume total responsabilidade pela aplicação do tratamento, há a percepção de que o nível de cobrança é superior no hospital estudado. De acordo com os entrevistados, isso se dá por três motivos. Primeiro, porque 0 conjunto de tecnologias oferece mais e melhores informações, o que permite um dimensionamento mais adequado dos riscos associados aos tratamentos. De acordo as palavras de um dos biomédicos, "[...] com as novas tecnologias é possível sair da ignorância [...]". Em segundo lugar, porque, conforme o exposto anteriormente, os pacientes são mais exigentes. E terceiro, porque os médicos conhecem e participam ativamente de todas as etapas do processo, aumentando as cobranças por um aperfeiçoamento contínuo.

As cinco constatações descritas acima foram compiladas com base nas entrevistas realizadas com a equipe de biomédicos e operadores. Portanto, as diferenças indicadas entre o serviço oferecido pelo hospital estudado e 0 de outras instituições em que esses profissionais atuam são baseadas, exclusivamente, na percepção dos mesmos. Não obstante, as similaridades encontradas nas declarações dos funcionários e o fato de que, no outro período, trabalham em, no mínimo, cinco instituições distintas, faz com que esses dados sejam relevantes para a análise em questão. 


\section{A ANÁLISE DOS RESULTADOS}

Os teóricos da Teoria da Contingência (BURNS; STALKER, 1961; PERROW,1967; WOODWARD,1965) sugeriram que 0 futuro pertenceria às empresas que adotassem 0 modelo orgânico, sendo que esse seria, eventualmente, imposto à administração pela evolução tecnológica. Dessa forma, a tecnologia seria uma fonte de inovação organizacional com poder suficiente para suplantar a lógica da Administração Científica de TAYLOR (1986).

Entretanto, mais recentemente, BARLEY (1986), WEICK (2001) e ZUBOFF (1988) analisaram os impactos das novas tecnologias em organizações de diversas indústrias e obtiveram resultados semelhantes indicando que:

a) A lógica da administração científica parece ter se enraizado nas pressuposições básicas, nos valores, nos artefatos e nos símbolos de um grande número de organizações, impedindo sua transformação com a implementação de novas tecnologias;

b) As novas tecnologias, caracterizadas pelo uso do meio eletrônico, apresentam uma dimensão abstrata, que exige dos indivíduos um maior esforço intelectual e emocional para interpretá-la e desenvolver significados;

c) Os autores apresentam evidências que comprovam que a tecnologia, ao mesmo tempo, afeta e é afetada pelo ambiente organizacional, ou seja, não é neutra como previam os teóricos da Teoria da Contingência;

d) As teorias das organizações não têm sido capazes de fornecer conceitos que expliquem a totalidade dos efeitos adversos, oriundos da adoção de novas tecnologias por parte das empresas.

ZUBOFF (1988) desenvolveu sua pesquisa nos setores industrial e de serviços e contemplou os efeitos organizacionais das novas tecnologias para dois ambientes: o fabril e o escritório administrativo. A autora apresentou evidências para concluir que as novas tecnologias, de fato, apresentam um potencial transformador, capaz de desencadear um processo de inovação organizacional, cujo resultado seria uma melhor adaptação às exigências do ambiente externo e um contexto social mais satisfatório para os funcionários. No entanto, o desabrochar desse potencial depende da maneira como as organizações e seus membros lidam com três dilemas fundamentais que emergem com a implementação das novas tecnologias. O primeiro diz respeito à mudança que se dá nas bases e na distribuição do conhecimento como resultado do trabalho que passa a ser mediado por computadores. 0 segundo refere-se às mudanças nas relações de autoridade, em que novas demandas por habilidades intelectuais, em todos os níveis organizacionais, poderão romper com a tradicional distinção entre funções operacionais e gerenciais. 0 terceiro dilema refere-se ao emprego de novas técnicas de controle por parte de gerentes que visam à manutenção das relações tradicionais de autoridade.

Para a autora, as novas tecnologias poderão oferecer, às organizações e seus membros, uma alternativa para o futuro que não esteja calcada na lógica da Administração Científica da automação e da centralização de controle e autoridade. Nesse contexto, a organização tenderia a evoluir para um modelo orgânico, no qual haveria uma distribuição mais eqüitativa de conhecimentos, habilidades técnicas e responsabilidades. A adoção de um modelo orgânico, por sua vez, resultaria em maior autonomia e satisfação para os funcionários no trabalho e maior eficiência organizacional. Essa transformação, entretanto, depende da capacidade que os gerentes possuem de perceber a 
oportunidade de informatização, para criar o contexto organizacional que a fomente e liderar a organização no processo de transformação. Os benefícios oriundos da implementação de tecnologias da informação dependem, ainda, de como os funcionários responderão às alternativas oferecidas.

Nas empresas em que os papéis organizacionais são mais rígidos e nas quais há uma resistência de seus membros, em especial da gerência, para lidar com os três dilemas apresentados por ZUBOFF (1988), as tecnologias tendem a ser empregadas para confirmar a centralização da autoridade e do poder, para aumentar o controle sobre as atividades dos funcionários e manter 0 conhecimento sob o domínio de poucos. Dessa forma, a tecnologia é implementada com o objetivo de manter e aprofundar o status quo. Assim, há um aumento da automação, maior divisão do trabalho e as técnicas de controle são aprimoradas, visando garantir à gerência sua supremacia. Nessas condições, é natural que os funcionários resistam aos controles e procedimentos impostos pelas novas tecnologias, uma vez que eles representam uma redução na autonomia, no grau de responsabilidade e nos conteúdos de seus trabalhos.

Segundo BARLEY (1986), WEICK (2001) e ZUBOFF (1988), a não-compreensão do potencial transformador das novas tecnologias e de sua capacidade de informatizar, bem como a não-adoção de uma estratégia de implementação que contemple as características do contexto social poderão resultar em efeitos adversos e conseqüências inesperadas para as organizações. Nas palavras de ZUBOFF (1988):

\footnotetext{
"[...] sofreremos com as conseqüências inesperadas da mudança porque não teremos compreendido esta nova tecnologia, e como ela difere das anteriores. Ao negligenciar a capacidade singular de informatização das novas tecnologias e ignorar a necessidade de uma nova visão do trabalho e da organização, teremos perdido os grandes benefícios que ela poderá oferecer. Teremos que encontrar formas de absorver as disfunções organizacionais, apagando fogos e fazendo curativos e viveremos em uma perplexidade que nos queimará lentamente." (p. 12).
}

O estudo de caso da Radioterapia oferece-nos uma nova abordagem, pois seus resultados demonstram que, nos contextos em que há um alto grau de complexidade social e técnica, a confiança precede a autonomia na condição de variável determinante da adaptação das organizações às exigências do meio. Enquanto na Teoria da Contingência (BURNS; STALKER, 1961; PERROW, 1967; WOODWARD, 1965) e nas análises de ZUBOFF (1988) a flexibilização de papéis organizacionais e 0 aumento da autonomia dos indivíduos é percebida como condição necessária para a evolução em direção a um modelo mais orgânico, no caso da Radioterapia, há evidências para concluir que a confiança entre os membros da organização e a confiabilidade nos sistemas peritos foram as variáveis que deram origem à adaptação organizacional.

As lideranças foram capazes de perceber que a confiança nas pessoas e nos sistemas é um fator preponderante para atingir seu principal objetivo, isto é, o de manter uma reputação de qualidade e superioridade tecnológica no mercado. Além disso, a confiança aparece como uma fonte de renovação contínua do comprometimento dos profissionais na área. Existem evidências para concluir que a maneira como os profissionais da área responderam às oportunidades oferecidas pelas novas tecnologias, em especial a transformação do conhecimento e o emprego de novas técnicas de controle, fez emergir um alto grau de confiança entre as partes e de confiabilidade nos sistemas, o que resultou em redução dos riscos a níveis aceitáveis.

Os relatos de funcionários da radioterapia, que exercem funções similares em outras instituições, indicam que a confiança no sistema (nas tecnologias, nos processos que determinam seu uso e nos membros da equipe) é de extrema relevância para a redução de risco. Ao baixar os riscos para níveis aceitáveis, é possível aumentar as chances de cura de um paciente. Assim, minimizam-se as emoções intensas vivenciadas pelos profissionais envolvidos no tratamento, aumentando a satisfação no trabalho e a confiança nas pessoas e nos sistemas. 
O aumento da confiança, neste caso, parece estar associado a:

a) Disponibilidade de novas informações que permitem um avanço no conhecimento das doenças e suas condições de cura;

b) o desenvolvimento de novas habilidades intelectuais por parte dos integrantes da equipe para, a partir das informações, construir novas bases de conhecimento;

c) a disposição de médicos e físicos para compartilharem os novos conhecimentos com biomédicos e técnicos que operacionalizam as novas tecnologias;

d) maior controle sobre os parâmetros do tratamento, durante sua execução, por meio do uso de modernas tecnologias e de uma estrutura organizacional adequada.

De fato, os resultados deste estudo de caso indicam que o aumento do controle, que é exercido pelas novas tecnologias e pelos procedimentos operacionais adotados, é fonte de satisfação para os membros da equipe do serviço de radioterapia. A disposição dos médicos e físicos para compartilhar seus conhecimentos e capacitar os profissionais técnicos e biomédicos permitiu a conscientização, por parte dos funcionários, do poder das novas tecnologias e do alto grau de risco associado ao uso das mesmas. Por um lado, as tecnologias têm condições de disponibilizar informações mais precisas sobre o diagnóstico da doença e de permitir o planejamento de um tratamento mais eficiente, o que aumenta as chances de cura e reduz os efeitos colaterais associados à radiação. Por outro, um tratamento mal planejado e mal executado pode representar importantes riscos à saúde já debilitada do paciente.

Os equipamentos de radioterapia e os sistemas de gerenciamento asseguram que 0 tratamento será realizado dentro dos parâmetros previstos na fase de planejamento. 0 operador não possui autonomia para dar andamento a um tratamento cujos parâmetros não estejam dentro da margem de erro permitida. Ademais, as tecnologias empregadas controlam todas as etapas do planejamento e do tratamento, bem como as ações dos responsáveis. Na perspectiva de BARLEY (1986), WEICK (2001) e ZUBOFF (1988), esse aumento de controle representaria menor autonomia para os funcionários, mais centralização de autoridade, menos flexibilidade organizacional e, por conseqüência, menor satisfação e capacidade de eficiência organizacional. Entretanto, os resultados deste estudo de caso apontam para um resultado diferente.

Pelo visto, o aumento do controle aumenta a confiança entre os membros da organização e das pessoas nos sistemas. Por conseguinte, há uma redução no grau de ansiedade gerado pela atividade, fazendo com que os profissionais sintam-se livres para analisar as complexas informações disponibilizadas pelas tecnologias, aprimorando continuamente a qualidade dos serviços prestados, tanto pela redução permanente das margens de erro quanto pela exploração do potencial transformador das novas tecnologias.

\section{A CONFIANÇA EM PERSPECTIVA}

GIDDENS (1991), em sua obra As Conseqüências da Modernidade, aponta para a relevância da construção da confiança na sociedade moderna e, em especial, nas situações em que os sistemas peritos são empregados. Para o autor, a confiança existe quando 'se acredita' em alguém ou em algum princípio. É a 'fé', na qual a segurança, adquirida em resultados prováveis, expressa compromisso com algo além da compreensão cognitiva. A existência de sistemas peritos, como é o caso do serviço de radioterapia estudado, só é viável a partir do momento em que os leigos possam renovar 
continuamente sua confiança nos mesmos, e isso só ocorre quando tais sistemas funcionam de acordo com as expectativas dos usuários.

Outros autores sugerem que, na modernidade, a confiança é central para o bom desempenho sócio-econômico (DASGUPTA, 1988; GAMBETTA, 1988; WILLIAMS, 1973). Para GAMBETTA (1988), a confiança poderá ser reproduzida intencionalmente na sociedade moderna para tornar o sistema econômico mais saudável e sustentável no longo prazo. Segundo o autor, os indivíduos racionais buscam informações e evidências para saber se os agentes econômicos, com os quais transacionam, irão cooperar e cumprir com os compromissos assumidos e, por outro lado, oferecem evidências sobre sua própria confiabilidade. Nesse contexto, a reputação passa a exercer um papel importante, uma vez que carrega informações sobre nossa confiabilidade e a dos outros.

Segundo DASGUPTA (1988), a confiança pode ser definida como a expectativa que se tem quanto às ações que outras pessoas escolherão e que influenciarão nossas próprias ações, sendo que as últimas devem ser exercidas antes de termos a oportunidade de monitorar as primeiras. $O$ fato de não ser possível monitorar diretamente as ações de outros agentes econômicos, e de termos de agir com informações insuficientes, torna o conceito de confiança fundamental para as organizações modernas, transformando as novas técnicas de controle - oriundas da tecnologia da informação - em um importante instrumento para monitorar as ações dos outros que, por ventura, estejam dispersos, no tempo e no espaço.

LUHMANN (1988), no artigo Familiarity, Confidence, Trust: Problems and Alternatives, faz uma distinção adicional entre confiabilidade em sistemas e confiança em pessoas. A confiabilidade em sistemas ocorre quando os indivíduos estão diante de eventos contingentes que têm pouca probabilidade de frustrá-los. São situações em que os sujeitos negligenciam a possibilidade de 0 resultado não se concretizar por não possuírem alternativa. A confiança em pessoas, por sua vez, requer o engajamento individual e pressupõe uma situação de risco, ou seja, o indivíduo pode evitar 0 risco, porém deve estar disposto a abrir mão de vantagens associadas à ação que deliberadamente escolhe não realizar. Segundo o autor, é possível desenvolver a confiança em pessoas no nível micro e proteger o sistema da perda de confiança no nível macro.

As teorias de DASGUPTA (1988), GAMBETTA (1988), GIDDENS (1991), LUHMANN (1988) auxiliam na compreensão do papel da confiança no serviço estudado. Estamos diante de uma organização de estrutura funcional de alta complexidade técnica e social, na qual a interdependência entre as pessoas e os papéis que exercem é vital para o sucesso do tratamento de radioterapia. Um pequeno erro de uma das partes prejudicará o resultado de todos, podendo, inclusive, ser fatal para 0 paciente. De fato, a estrutura do serviço guarda semelhanças com a definição de solidariedade orgânica de DURKHEIM (2002):

[...] Efetivamente, cada um depende, por um lado, mais estreitamente da sociedade onde 0 trabalho é mais dividido e, de outro, a atividade de cada um é tanto mais pessoal quanto mais especializada ela seja...Aqui, pois a individualidade do todo aumenta ao mesmo tempo que as partes; a sociedade se torna mais capaz de se mover em conjunto, ao mesmo tempo que cada um de seus elementos tem mais movimentos próprios.... (p. 83).

Entretanto, os membros da organização não possuem mecanismos para monitorar e controlar as atividades de seus colegas, nem mesmo os médicos, principais detentores de autoridade e poder nas organizações hospitalares. Nesse contexto, os controles oferecidos pelas novas tecnologias poderão proporcionar uma garantia de que 'os outros' realizarão suas atividades de acordo com as expectativas e contribuirão para reduzir o risco de erros no planejamento e execução dos tratamentos. 


\section{CONCLUSÃO: INTEGRANDO A VARIÁVEL CONFIANÇA NO QUADRO DA TEORIA ORGANIZACIONAL}

\subsection{CONTRIBUIÇÃO DA TEORIA DA CONTINGÊNCIA}

A Teoria da Contingência, que surge na década de 50, trouxe contribuições importantes para a Teoria Organizacional na medida em que foi capaz de integrar as abordagens contraditórias da Escola Clássica de Administração de TAYLOR (1986) e da Escola de Relações Humanas de MAYO (1960). A hipótese central dos teóricos da Contingência (BURNS; STALKER, 1961; LAWRENCE; LORSCH, 1967; PERROW, 1967; WOODWARD, 1965) é de que as tarefas de baixa incerteza poderão ser executadas mais eficazmente por meio de uma hierarquia centralizada, similar à apresentada pela Escola Clássica de Administração. Com o aumento da incerteza das tarefas, fruto de inovações (por exemplo, a incorporação de novas tecnologias), a hierarquia precisa perder um pouco de controle e ser substituída por uma rede de equipes flexíveis e participativas, similar à proposta pela Escola de Relações Humanas.

$\mathrm{Na}$ base do conceito da contingência está a incerteza da tarefa, cujo significado deriva da concepção de que quanto mais incerta a tarefa, mais informações têm de ser processadas. Isso, por sua vez, tende a moldar as estruturas de controle e de comunicação. As organizações que lidam com a incerteza têm de se valer de procedimentos especializados, o que exige uma flexibilização da estrutura hierárquica mecânica em direção à organização orgânica, pois parte do conhecimento necessário para a execução eficiente das tarefas poderá estar localizado nos níveis hierárquicos mais baixos da organização.

O grau de incerteza da tarefa é determinado pela inovação, a qual reflete fatores ambientais como, por exemplo, o lançamento de novos produtos por parte dos concorrentes ou a introdução de novas tecnologias comercialmente disponíveis. Na perspectiva dos teóricos da Contingência, fatores ambientais poderão levar a organização a aumentar o grau de inovação pretendido, exigindo a adoção de uma estrutura orgânica para acomodar o aumento no grau de incerteza da tarefa. Logo, em ambientes turbulentos, a maior complexidade organizacional (e da tarefa) requer uma estrutura orgânica mais flexível e adaptável às exigências externas. Em ambientes estáveis, porém, há um baixo grau de complexidade organizacional, no qual é possível adotar um modelo mecânico como é o caso dos sistemas fabris de produção em massa.

$\mathrm{Na}$ visão dos autores da Teoria da Contingência (BURNS; STALKER, 1961; LAWRENCE; LORSCH, 1967; PERROW, 1967; WOODWARD, 1965), a tecnologia representa um fator ambiental que, eventualmente, conduz a organização à inovação e à adoção de um modelo orgânico mais flexível, eficiente e satisfatório para seus membros. As tecnologias aumentam a incerteza da tarefa e a complexidade do contexto organizacional à medida que disponibilizam novas informações e transformam a infra-estrutura do trabalho. Dessa forma, a não-adoção de um modelo orgânico, por parte das organizações, representaria um mis-fit, isto é, uma inadequação que prejudica a eficiência. Logo, para sobreviver, a organização precisa evoluir do modelo mecânico para o orgânico.

A contribuição da Teoria da Contingência para a análise organizacional está, portanto, na sua capacidade de reconhecer que as organizações apresentam diferenças estruturais em função do ambiente no qual atuam e da complexidade organizacional que dele decorre. Assim, os autores concluem que modelos organizacionais distintos podem e devem ser adotados para adequar a organização às necessidades ambientais. Ademais, autores como PERROW (1967) e WOODWARD (1965) desenvolveram pesquisas relevantes sobre os efeitos da evolução tecnológica para as 
estruturas organizacionais e demonstraram que a tecnologia pode representar uma fonte importante de inovação.

A despeito de suas contribuições, os autores da Teoria da Contingência não consideraram os aspectos do contexto social e da cultura organizacional, que podem vir a representar um empecilho para a inovação e, conseqüentemente, para a adaptação das empresas ao ambiente externo. Na percepção de PERROW (1967) e WOODWARD (1965), a tecnologia, por si só, seria capaz de transformar as organizações mecânicas em orgânicas. BARLEY (1986), WEICK (2001), ZUBOFF (1988) demonstraram que a evolução tecnológica é contingente ao contexto social e cultural das organizações.

\subsection{NOVAS TECNOLOGIAS: DOIS CAMINHOS}

ZUBOFF (1988), ao apresentar os resultados de sua pesquisa, faz uma contribuição teórica relevante para a Teoria das Organizações. A autora reconhece que as novas tecnologias, ou tecnologias da informação, apresentam um potencial transformador, uma vez que têm a capacidade de informatizar e automatizar procedimentos. A informatização poderá alterar a forma de aquisição e distribuição de conhecimento ao textualizar o trabalho dos membros de uma organização e torná-los transparentes e acessíveis a todos. Como resultado, os papéis organizacionais poderão tornar-se mais flexíveis e as relações de autoridade e poder mais democráticas, o que levaria a organização a um modelo orgânico e mais apropriado para explorar o potencial de inovação das novas tecnologias.

No entanto, a autora apresenta evidências que lhe permitem concluir que a inovação, oriunda da introdução de novas tecnologias, é contingente às variáveis do contexto social e cultural das organizações. Na perspectiva de ZUBOFF (1988), as novas tecnologias transformam as organizações, porém a direção dessa transformação não é necessariamente para o modelo orgânico, conforme previam os teóricos da Contingência.

Segundo a autora, o desabrochar do potencial transformador das novas tecnologias depende da existência de um contexto social que permita aos gerentes: reconhecer as oportunidades oferecidas pelas novas tecnologias, criar um ambiente favorável para a implementação das mesmas e conduzir os membros da organização à inovação. Para ZUBOFF (1988), isso só poderá ocorrer em um contexto no qual haja autonomia em todos os níveis hierárquicos e os controles sejam flexibilizados. Caso contrário, a organização sofrerá um retrocesso.

Na visão da autora, a adoção de tecnologias da informação para aprimorar a automatização e reafirmar o modelo mecânico, visando assegurar a autoridade e o poder dos gerentes através do uso de sofisticados mecanismos de controle, fará a organização retroceder. A não-compreensão, por parte dos membros da organização, das características das novas tecnologias tem como conseqüência 0 surgimento de problemas inesperados e adversos, os quais não são passíveis de análise e solução com o emprego de conceitos existentes em Teoria das Organizações (WEICK, 2001; ZUBOFF, 1988).

Em suma, para ZUBOFF (1988), assim como para os autores da Teoria da Contingência (PERROW, 1967; WOODWARD, 1965;), as novas tecnologias transformarão a organização. A Teoria da Contingência pressupõe que a tecnologia é determinista, pois eventualmente imporá, às organizações, o modelo orgânico, considerado mais eficiente e mais adaptável às exigências do ambiente externo. ZUBOFF (1988), por sua vez, reconhece o potencial transformador das tecnologias, em especial da tecnologia da informação, e sugere que o modelo mecânico será suplantado. A evolução para o modelo orgânico, porém, dependerá da existência, no contexto social e cultural, de condições que permitam o reconhecimento da oportunidade e ofereçam autonomia para os membros da organização explorá-la. Na perspectiva da autora, o modelo mecânico poderá ser suplantado por 
uma inadequação organizacional em função do surgimento de inúmeros problemas não contemplados pela administração.

Pode-se concluir que a abordagem de ZUBOFF (1988) contribuiu de maneira significativa para ampliar o conhecimento sobre os efeitos da tecnologia para as organizações. A autora defende a inclusão de aspectos relevantes do contexto social na análise e sugere que o futuro das organizações depende, não apenas de fatores do ambiente externo, mas de profundas alterações em suas relações de autoridade, poder, formas de adquirir e distribuir conhecimento. A autora enfatiza a necessidade de as organizações desenvolverem contextos sociais nos quais seus membros possuam autonomia suficiente para desenvolver novas habilidades intelectuais e tenham capacidade de participar ativamente do processo de inovação.

O valor da contribuição de ZUBOFF (1988) é inestimável para a Teoria das Organizações, entretanto, o estudo de caso da Radioterapia, apresentado nesta pesquisa, demonstra que há exceções na lógica apresentada pela autora que devem ser consideradas.

\subsection{CONTRIBUIÇÃO TEÓRICA DA PESQUISA}

Os resultados do estudo de caso da Radioterapia, apresentado neste trabalho, indicam que, em algumas circunstâncias, o aumento do controle é desejado pelos atores dentro e fora das organizações, o que contraria a lógica de ZUBOFF (1988). A redução da autonomia, que se deu com 0 emprego de sofisticadas técnicas de controle oriundas das tecnologias clínicas, permitiu aumentar 0 grau de confiança entre os funcionários e dos pacientes no serviço.

Os membros da organização da Radioterapia, em todos os níveis, estão dispostos a serem vigiados, monitorados e acompanhados pelos mecanismos de controle das novas tecnologias. Isso Ihes confere maior segurança em suas atividades, pois reduz os riscos associados à execução e planejamento do tratamento, aumentando as chances de cura dos pacientes. Ao garantir que todos realizem suas atividades dentro do previsto, a implementação de controles sofisticados permitiu que se estabelecesse uma relação de confiança entre os membros da organização.

$O$ alto grau de interdependência entre os membros da organização, de especialização técnica das funções e a complexidade envolvida nos tratamentos de radioterapia faz a confiança emergir como fator essencial para o bom desempenho organizacional. Isto é, a construção das relações de confiança permitiu que se desenvolvesse um trabalho em equipe, que as responsabilidades e os conhecimentos fossem adequadamente compartilhados para beneficiar o paciente. Como resultado, tem-se uma organização flexível e participativa, na qual a motivação dos funcionários é continuamente renovada através da manutenção das relações de confiança. $O$ excelente desempenho organizacional atingido pode ser comprovado pela reputação da instituição no setor de tratamentos de radioterapia.

Os resultados do estudo de caso da Radioterapia permitem concluir que, em determinados contextos organizacionais de alta complexidade técnica e social, o desenvolvimento intencional das relações de confiança, através da implementação de controles, pode preceder a autonomia como variável chave de adaptação organizacional. Nesse caso, os controles não são implementados para assegurar a manutenção das relações de autoridade e poder existentes na organização, mas para tornar transparente e previsível a ação de seus membros. A adoção de novas tecnologias e o trabalho mediado pelo computador tendem a tornar o ambiente organizacional mais complexo, as ações de seus membros mais abstratas e difíceis de monitorar. Dessa forma, torna-se imprescindível 0 comprometimento dos líderes organizacionais com a reconstrução das relações de confiança, as quais estimularão a eficiência interna e externa da organização. 


\section{REFERÊNCIAS}

BARLEY, S. R. Technology as an Occasion for Structuring: Evidence from Observations of CT Scanners and the Social Order of Radiology Departments. Administrative Science Quarterly. Ithaca, v. 31(1), p.78-108, Março 1986.

BURNS, T.; STALKER, G. The Management of Innovation. 2a Edição. Londres: Tavistock, 1961.

DASGUPTA, P. Trust as a Commodity. In: GAMBETTA, D. Trust: Making and Breaking Cooperative Relations. 1르로ãa. Nova York: Basil Blackwell, 1988. Capítulo 4,p. 49-72.

DONALDSON, L. Teoria da Contingência Estrutura. In: CALDAS, M.; FACHIN, R.; FISCHER,T. (Org.) Handbook de Estudos Organizacionais: Modelos de Análise e Novas Questões em Estudos Organizacionais. 1a Edição. São Paulo: Atlas, 1998. v.1.

DURKHEIM, E. Solidarité Mécanique ou Par Similitudes. Tradução: Laura Natal Rodrigues. In: RODRIGUES, J.A.; FERNANDES F. (Org.). Coleção Grandes Cientistas Sociais: Durkheim Sociologia. ga Edição. São Paulo: Ática, 2002.

EISENHARDT, K. M. Building Theories from Case Study Research. Academy of Management Review. Briarcliff Manor, v. 14 (4), p. 532-550, 1989.

GAMBETTA, D. Can We Trust Trust?. In: GAMBETTA, D. Trust: Making and Breaking Cooperative Relations. 1를 Edição. Nova York: Basil Blackwell, 1988. Capítulo 13, p. 213-237.

GAMBETTA, D. Mafia: the Price of Mistrust. In: GAMBETTA, D. Trust: Making and Breaking Cooperative Relations. 1ª Edição. Nova York: Basil Blackwell, 1988. Capítulo 10, p. 158-175.

GIDDENS, A. As Conseqüências da Modernidade. Tradução: Raul Fiker. 1a Edição. São Paulo: Unesp, 1991.

GIURLIANI, S. Com a Faca mas Sem o Queijo na Mão. COMPUTERWORLD. Rio de Janeiro, 20 de Novembro de 2002, Especial de Saúde, n.376, p.24-31.

HATCH, M. J. The Dynamics of Organizational Culture. The Academy of Management Review. Briarcliff Manor, v. 18 (4), p. 657-693, 1993.

HEALTH MANAGEMENT TECHNOLOGY. Web has Changed Medical Practices. Atlanta, v. 23 (10), p. 12, Outubro, 2002.

LAWRENCE, P.; LORSCH, J. Organizations and Environment. Cambridge: Harvard University Press, 1967.

LUHMANN, N. Familiarity, Confidence, Trust: Problems and Alternatives. In: GAMBETTA, D. Trust. Making and Breaking Cooperative Relations. 1ㄹ Edição. Nova York: Basil Blackwell, 1988. Capítulo 6,p. 94-108.

MOTTA, F. C. P. Teoria Geral da Administração: uma introdução. 14a Edição. São Paulo: Pioneira, 1987. 
PERROW, C. A Framework for Comparative Organizational Analysis. American Sociological Review. Washington. v. 32, p. 194-208, 1967.

SCHEIN, E. H. Coming to a New Awareness of Organizational Culture. Sloan Management Review. Massachussets, v. 25, p.3-16, 1984.

TAYLOR, F. W. Princípios de Administração Científica. Tradução: Arlindo Vieira Ramos. 7a Edição. São Paulo: Atlas, 1986.

THOMPSON, J. Organizations in Action. 1a Edição. Nova York: McGraw Hill, 1967.

VASCONCELOS, F. C. Racionalidade, Autoridade e Burocracia. In: II ENCONTRO NACIONAL DE ESTUDOS ORGANIZACIONAIS, 2002, Recife. CDROM do II Encontro Nacional de Estudos Organizacionais, 2002, p. 1-15.

WEICK, K. Technology as Equivoque. In: Making Sense of the Organization. Oxford: Blackwell, 2001, p. 148-175.

WILLIAMS, B. Formal Structures and Social Reality. In: GAMBETTA, D. Trust: Making and Breaking Cooperative Relations. 1aㅡ Edição. Nova York: Basil Blackwell, 1988. Capítulo 1,p. 3-13.

WOODWARD, J. Management and Technology. 1를ㄷão. Londres: HMSO, 1958.

WOODWARD, J. Industrial Organization: theory and practice. 1르로ão. Londres: Oxford University Press, 1965.

YIN, R. K. Estudo de Caso: Planejamento e Métodos. Tradução: Daniel Grassi. 2ª Edição. Porto Alegre: Bookman, 2001.

ZUBOFF, S. In The Age of The Smart Machine: The Future of Work and Power. 1 a Edição . Nova York: Basic Books, 1988.

\title{
NEW TECHNOLOGIES AND ORGANIZATION'S TRUST: A CASE STUDY IN THE CONTEXT OF HEALTH ORGANIZATION
}

\begin{abstract}
The rate by which the implementation of new technologies has grown in all sectors of the economy increased organizational complexity and uncertainty. As a result, companies and their members now face a number of new challenges. This paper analyzes one case study that contemplates the implementation of new technologies in a radiotherapy unit of a large private health care organization. Its main objective is to analyze the growth in social complexity, which derives from the use of technologies and to verify its implications for organization. Furthermore, it intends to investigate the role of trust as a variable of adjustment of the organization to the external environmental needs.
\end{abstract}

Key words: Organization Studies. Innovation. New Technologies. Trust.

Submissão: março de 2006 Aceite: setembro de 2006 